\title{
Failure analysis of microfabricated iridium ultramicroelectrodes in chloride media
}

\author{
Melissa A. Nolan, Samuel P. Kounaves * \\ Department of Chemistry, Pearson Chemistry Lab, Tufts University, Medford, MA 02155, USA
}

Received 27 January 1998; received in revised form 18 May 1998

\begin{abstract}
This study investigates the failure mechanisms for an electrochemical sensor consisting of an array of microlithographically fabricated iridium ultramicroelectrodes (UME) on a silicon wafer. It has been noted that the use of these sensors during voltammetric determination of heavy metal ions in the presence of $>0.1 \mathrm{M} \mathrm{Cl}^{-}$results in loss of response and general failure of the sensor. The addition of $\mathrm{Hg}$ or $\mathrm{Ag}$ to the $\mathrm{Cl}$ containing solution caused massive accumulations on the exposed $\mathrm{Ir}$ surfaces, which were identified using auger scanning electron microscopy (SEM). Under analytical conditions this failure does not appear to be due to migration of $\mathrm{Cl}^{-}$but to the penetration of $\mathrm{Cl}^{-}$through pin-holes in the insulating layer and subsequent reaction with the $\mathrm{Al}$ interconnect traces on the chip. Consequently, the $\mathrm{Al}$ traces dissolved and hydrogen gas was evolved. This reaction generates a potential which is transmitted to exposed Ir and consequently metal ions present in the solution are then reduced onto these surfaces. Several insulating layers, $\mathrm{SiO}_{2}(5000 \AA)$ and $\mathrm{Si}_{3} \mathrm{~N}_{4}(1500,2500$ and $5000 \AA)$ were also used, but failure occurred with all. It is critical that either sub-micron sized pin-holes during the fabrication process be better controlled or that the $\mathrm{Al}$ interconnect traces be replaced by Au. The use of Au however may still allow these unwanted micron-sized UMEs to interfere with the electrochemical analysis. (C) 1998 Elsevier Science S.A. All rights reserved.
\end{abstract}

Keywords: Ultramicroelectrode; Microfabricated; Silicon wafer; Electroanalysis

\section{Introduction}

In recent years, the development of microlithographically fabricated sensors used for electroanalysis has increased dramatically [1-11]. Recently they have been shown to be ideal for use on-site and/or in-situ for fast screening of groundwater contaminated with heavy metal ions [9]. Microlithography has the advantage of creating well-defined and reproducible geometries of micron dimensions that can be utilized to fabricate ultramicroelectrodes (UME). Several different types of materials such as gold, platinum, iridium and carbon have been utilized as the electrode substrate. Most of these sensors consist of an electroactive area (working electrode) which is connected to a bonding pad by an interconnect trace. Some requisites for the choice of the interconnect metal are high conductivity, ease of deposition and cost. The interconnect trace is protected with

\footnotetext{
*Corresponding author. Tel.: + 16176273124
}

an insulating material which prevents any reaction between the solution and the underlying metal. Several commonly used insulating materials include silicon nitride $\left(\mathrm{Si}_{3} \mathrm{~N}_{4}\right)$, silicon dioxide $\left(\mathrm{SiO}_{2}\right)$ and polyimide. The importance of the interconnect metal is often overlooked in the fabrication process. Even though gold is the most often used for the trace connections [6-11], a substantial number of sensors use other metals or do not report the interconnect metal [1-4].

In our laboratory, mercury is electrochemically deposited onto the iridium UME arrays (UMEAs) for the voltammetric stripping analysis of heavy metal ions. During routine experiments with these sensors we observed a partial coverage of the iridium surface with a material, believed to be $\mathrm{Hg}_{2} \mathrm{Cl}_{2}$ (calomel) [12], that resulted in a decreased or distorted signal. For such a problem, Jagner et al. [14] recommended that the mercury plating solution contain $4 \mathrm{M}$ chloride to prevent calomel formation. However, when an array was placed in a solution containing $8 \mathrm{mM} \mathrm{Hg}$ in $0.1 \mathrm{M} \mathrm{HClO}_{4}$ and $4 \mathrm{M} \mathrm{NaCl}$, bubbles immediately appeared on the sur- 
face of the sensor. Ultimately, the sensor failed, mercury would not electrochemically deposit on the array and extensive accumulations appeared on the exposed iridium UMEA surface even when no potential was being applied.

In this paper, we present the investigation into the failure mechanism of the sensor consisting of the microlithographically fabricated iridium-based UMEA $[12,13]$ with an aluminum interconnect, in different chloride containing media. In addition, two types of insulating layers, silicon nitride $(1500,2500$ and 5000 $\AA$ ) and silicon dioxide (5000 $⿱$ A) were also investigated.

\section{Experimental}

\subsection{Sensor fabrication and initial validation}

Since the fabrication process of the sensor has been described elsewhere [12,13], only a brief overview is summarized below. After several depositions of photoresist and patterning on the silicon wafer, layers of titanium (300 ̊), iridium (1000 ̊) and aluminum were separately deposited by electron bean evaporation. The conducting layers were then protected and insulated by a layer of either silicon nitride (1500 or $2500 \AA)$ or silicon dioxide $(5000 \AA)$ which was deposited by low temperature plasma enhanced chemical vapor deposition (PECVD) with a maximum temperature of $300^{\circ} \mathrm{C}$. No other thermal treatments were carried out on the insulating layer. The stress of the insulating layer was $1 \times 10^{10}$ dynes per $\mathrm{cm}^{2}$. The insulating layer was plasma etched at a rate of $50 \AA$ per min. The sensor consists of 20 or 25 iridium UME with a diameter of $10 \mu \mathrm{m}$ acting as the working electrodes. Two designs were used but no difference in performance was observed. Both designs consisted of the UMEA and an on-chip iridium reference and counter electrode. The on-chip counter and reference electrodes were not used during these experiments. As diagrammed in Fig. 1, an insulating layer of silicon nitride or silicon dioxide covered the

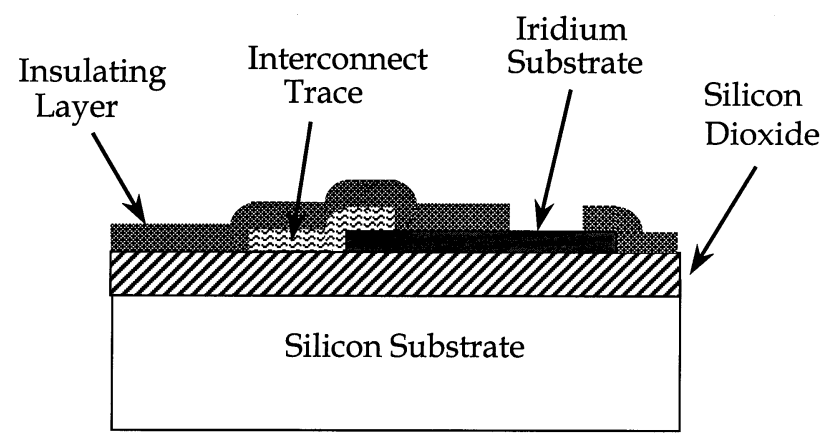

Fig. 1. Cross sectional view of the Ir-based ultramicroelectrode array heavy metal ion sensor. The active sensing element is a semisphere of $\mathrm{Hg}$ coated on top of the Ir substrate prior to the analysis. entire surface except for the electroactive iridium areas used as working, reference and counter electrodes and the bonding pads.

The arrays were stored in a solution with no applied potential unless otherwise noted. After the array had been stored in the solution for a given time, cyclic or linear scan voltammetry was used to test the electrochemical response of the UMEA. Cyclic voltammetry scans were carried out in $0.1 \mathrm{M} \mathrm{HNO}_{3}$ from -0.7 to $0.1 \mathrm{~V}$ at a scan rate of $100 \mathrm{mV} \mathrm{s}^{-1}$. When mercury was present in the chloride solution, linear scan voltammetry was carried out in $1 \mathrm{M} \mathrm{KSCN}$ and the potential was applied from -0.3 to $0.3 \mathrm{~V}$ at a scan rate of $20 \mathrm{mV}$ $\mathrm{s}^{-1}$.

\subsection{Instrumentation}

In situ observations were made with a CCD color video camera attached to a monitor and VCR. Ex situ observations were carried out with a Metaval-H (Leco/ Jena) inverted microscope equipped with a video processing system. A Nanoscope E atomic force microscope (AFM) (Digital Instruments, Santa Barbara, CA) was used to obtain micron-size resolution of the surfaces. Scanning electron microscopy (SEM) was carried out at the Center for Materials Science and Engineering at Massachusetts Institute of Technology (Cambridge, MA) with a Perkin Elmer/Physical Electronics Model 660 Scanning Auger Microprobe. All electrochemical experiments were carried out with an EG\&G PAR Model 273 potentiostat/galvanostat (EG\&G PARC, Princeton, NJ) interfaced to a DEC p420-SX microcomputer and using Model 270 Software.

\section{Results and discussion}

\subsection{Effect of chloride and acidic media}

Since the failure of the sensor occurred in a solution containing $8 \mathrm{mM} \mathrm{Hg}$ with $0.1 \mathrm{M} \mathrm{HClO}_{4} \mathrm{M}$ and $4 \mathrm{M}$ $\mathrm{NaCl}$, we initially suspected that the chloride might be responsible. To confirm this, a sensor was placed in a solution containing only $8 \mathrm{mM} \mathrm{Hg}$ and $0.1 \mathrm{M} \mathrm{HClO}_{4}$ $\mathrm{M}$ for $2 \frac{1}{2} \mathrm{~h}$. No accumulations appeared on the exposed iridium UMEs and the sensor gave a proper response. We therefore concluded at this point that the chloride ions appeared to be the cause for the sensors failure.

The chloride concentration was then varied in order to determine more precisely at what point the failure would occur. Sensors were placed for $2 \frac{1}{2} \mathrm{~h}$ in solutions containing $8 \mathrm{mM} \mathrm{Hg}$ and $0.1 \mathrm{M} \mathrm{HClO}_{4}$ with chloride concentrations from $1.0 \times 10^{-4}$ to $1 \mathrm{M}$. For chloride concentrations $<0.1 \mathrm{M}$, no accumulations were observed and a good electrochemical response was ob- 


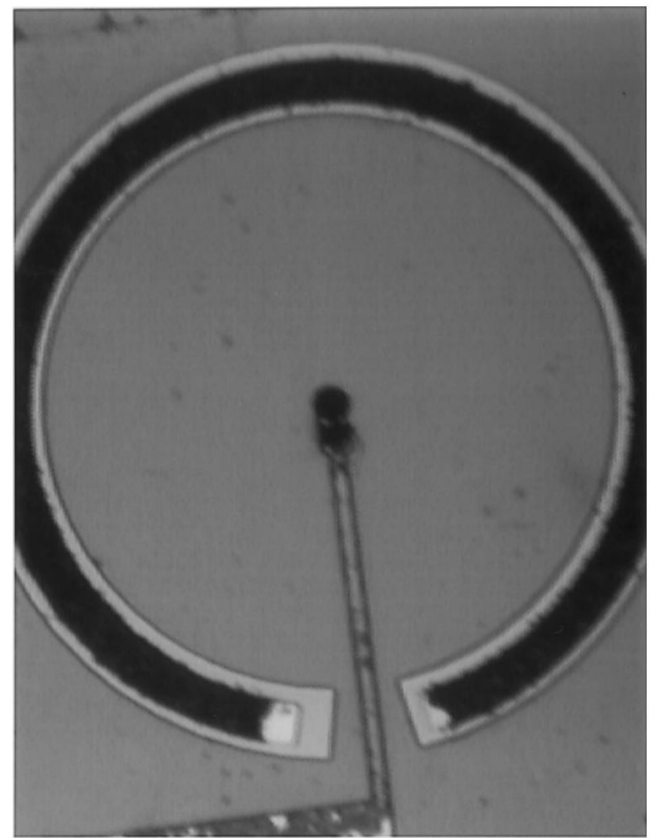

(A)

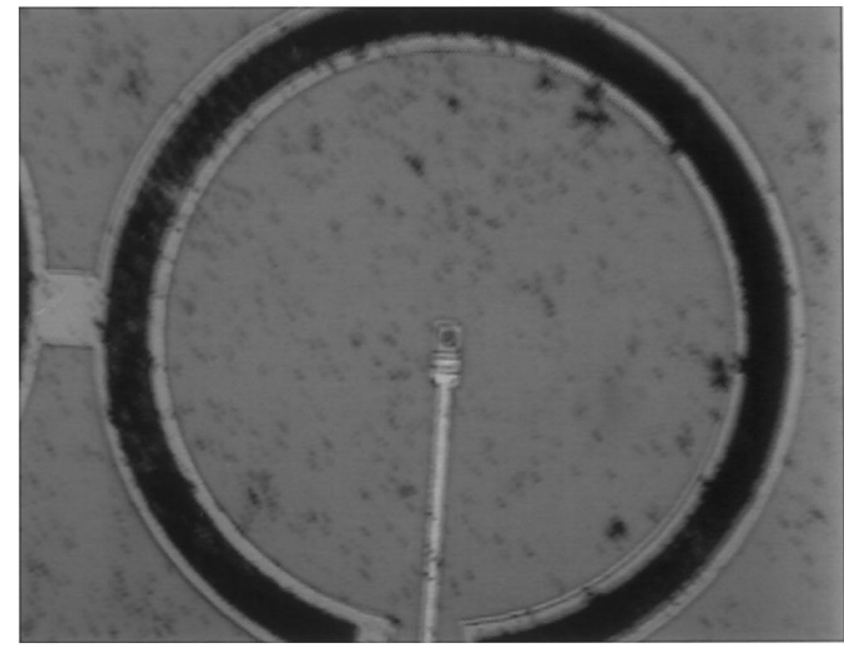

(B)

Fig. 2. (A) Array stored in $8 \mathrm{mM} \mathrm{Hg}$ in $0.1 \mathrm{M} \mathrm{HClO}_{4}$ and $4 \mathrm{M} \mathrm{NaCl}$ solution for $2 \frac{1}{2} \mathrm{~h}$. (B) Array stored in $8 \mathrm{mM} \mathrm{Hg}$ in $0.1 \mathrm{M} \mathrm{HClO} 4$ solution directly under a $\mathrm{Ag} / \mathrm{AgCl}(3 \mathrm{M} \mathrm{NaCl})$ reference electrode.

tained. For chloride concentrations $>0.1 \mathrm{M}$ the accumulations were very abundant, as shown in Fig. 2 (A, B) and no electrochemical response was obtained. Even though the accumulations appeared black or brown under the polarizing microscope, they were white when viewed with the naked eye.

The mercury solution was changed to confirm that only the chloride ions responsible for the failure of the sensor. However, eliminating the perchloric acid and using a solution containing $8 \mathrm{mM} \mathrm{Hg}$ in $0.1 \mathrm{M} \mathrm{NaCl}$ and acidified with hydrochloric acid, still caused sensor failure. Moreover, the same failure also occurred when potassium chloride was used instead of sodium chloride.

Acidity was another common element of all the solutions used in which the problem occurred. To determine if the low $\mathrm{pH}$ of the solutions contributed to the failure, a sensor was placed in a $0.1 \mathrm{M} \mathrm{NaCl}$ solution. After $2 \frac{1}{2} \mathrm{~h}$ in the chloride solution the sensor was tested electrochemically and proper electrochemical response was obtained. When it was stored in an acidified $0.1 \mathrm{M}$ $\mathrm{NaCl}$ solution for $2 \frac{1}{2} \mathrm{~h}$, no electrochemical response was obtained and no accumulations occurred on the exposed iridium UME surfaces. Therefore, both the chloride concentration and the acidity of the solutions directly contribute to sensor failure.

\subsection{Accumulations}

There were two conditions indicating the apparent failure of a sensor (1) no electrochemical response could be obtained (2) accumulations formed on the surfaces of the iridium UMEs. However, storage in an acidified $0.1 \mathrm{M} \mathrm{NaCl}$ solution prevented accumulations from forming, but still caused failure. Apparently, the accumulations formed only when mercury ions were present in the solution. To support this conclusion, a sensor was stored in a solution containing $8 \mathrm{mM} \mathrm{Hg}, 0.1 \mathrm{M}$ $\mathrm{HClO}_{4}$ and $4 \mathrm{M} \mathrm{NaCl}$, with no potential applied. Extensive accumulations appeared on the exposed iridium UME surfaces after just $15 \mathrm{~min}$ in the chloride solution.

The images obtained using AFM were too noisy and difficult to use for interpreting any of the features on the iridium UME surfaces. This lead us to conclude that the accumulations were probably in a liquid-like state. Auger SEM was then used to further analyze these accumulations. The SEM images, a typical one shown in Fig. 3, revealed the accumulations on the iridium UME surfaces to be roughly spherical. During auger analysis the sphere 'collapsed' leaving a solid residue which the analysis then identified to be mercury and chloride. Because of this 'collapse' we concluded that the accumulated material was probably composed of liquid mercury spheres with an outer coating of $\mathrm{Hg}_{2} \mathrm{Cl}_{2}$. The AFM images (Fig. 4) of the material remaining on the iridium UMEs revealed a cluster of pyramids. This type of structure formed under the same conditions has been previously analyzed and shown to be pyramidal crystals of $\mathrm{Hg}_{2} \mathrm{Cl}_{2}$ [12].

Since the catastrophic failure of the sensor occurred at relatively low chloride concentrations $(0.1 \mathrm{M})$, it was 


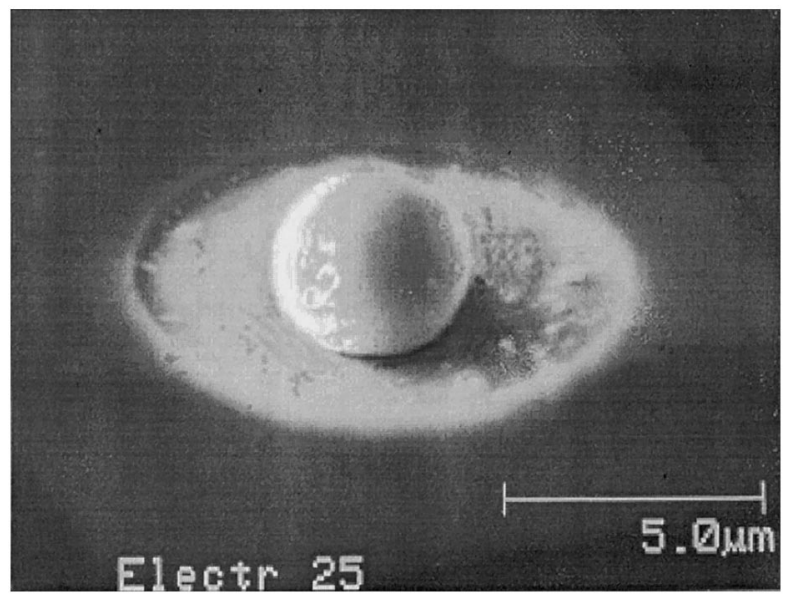

Fig. 3. An SEM image of an Ir-UME before analysis by Auger.

important to determine if leakage from a reference electrode containing chloride in its filling solution was enough to cause the same problem. To intensify the results of any leakage of chloride ions from the reference electrode, a sensor was placed in a solution of 8 $\mathrm{mM} \mathrm{Hg}$ in $0.1 \mathrm{M} \mathrm{HClO}_{4}$ directly under the junction of a $\mathrm{Ag} / \mathrm{AgCl}(3 \mathrm{M} \mathrm{NaCl})$ reference electrode. After $2 \frac{1}{2} \mathrm{~h}$, extensive accumulations were observed to form on the iridium UME surfaces, as seen in Fig. 2 (B). Linear scan voltammetry ( -0.3 to $0.3 \mathrm{~V}$ ) was carried out in 1 $\mathrm{M} \mathrm{KSCN}$ to try to remove the accumulations, but no electrochemical response could be obtained with this sensor. The amount of accumulations on the iridium UME surfaces depended on the distance from the junction of the reference electrode. The exposed iridium surfaces directly underneath the reference electrode were completely covered (Fig. 2B) while the iridium areas farthest away from the reference electrode (approx. $5 \mathrm{~mm}$ ) had minimal to no accumulations. Thus, as long as the sensor is far enough away from the reference electrode, chloride leakage should not cause the failure.
Since the accumulations seemed to occur only when both mercury and chloride ions were present in a solution, it seemed reasonable that they would not appear with only one component in solution. However, placing a sensor directly under a reference electrode in a solution containing only $0.1 \mathrm{M} \mathrm{HClO}_{4}$ for about $2 \frac{1}{2} \mathrm{~h}$ resulted in the formation of a thin film on the exposed iridium surfaces. This film though, differed substantially from the previously reported accumulations. Fig. 5 shows AFM images of a typical Ir UME surface (A) before and (B) after, exposure to the reference electrode. The Ir UME surface appears radically different. Analysis of this coating by Auger SEM identified the film components as silver and chloride.

The silver coating was not as abundant as the $\mathrm{Hg}_{2} \mathrm{Cl}_{2}$ accumulations since the leakage of silver ions from the reference electrode is minimal when compared with the amount of mercury $(8 \mathrm{mM})$ used in the chloride solution. To further verify that the low concentration of silver leaking from the reference electrode was the cause of the thin film, a sensor was placed in a saturated solution of silver chloride. After approximately an hour, all of the exposed Ir surfaces on the sensor were covered by a coating as shown in Fig. 6. Auger SEM analysis identified the material as silver with no chloride present. Thus, the amount of silver/mercury deposited on exposed iridium surfaces is directly proportional to the concentration of the metal in the chloride solution. The identity of the analyte, whether mercury or silver, did not make a difference since in either case the accumulations destroyed the electrochemical response.

\subsection{Failure mechanism of the UMEA sensor}

Even though the identity of the accumulations had been determined and the loss of sensor response attributed to their presence, their cause and confirmation of the failure mechanism remained.

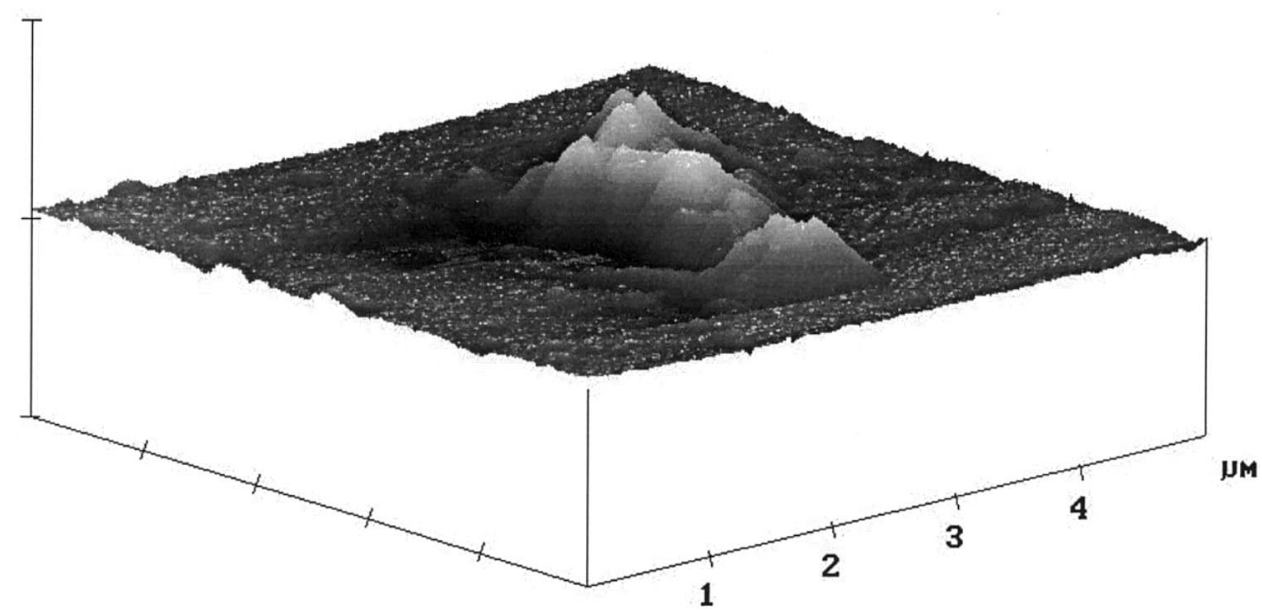

Fig. 4. AFM image of the material on the Ir-UME surface after the auger SEM was performed on the array shown in Fig. 3. 


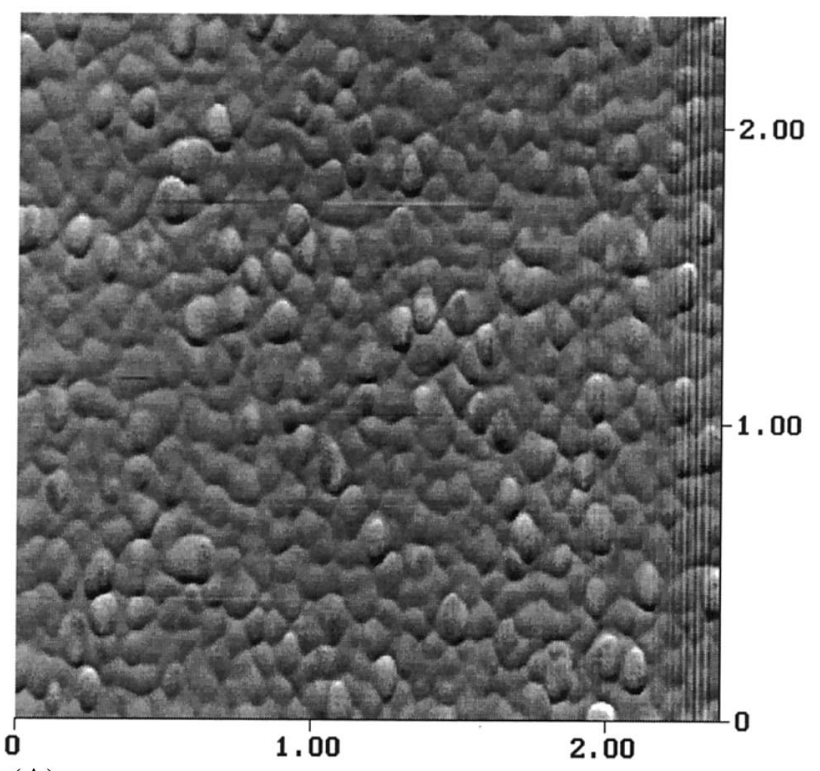

(A)

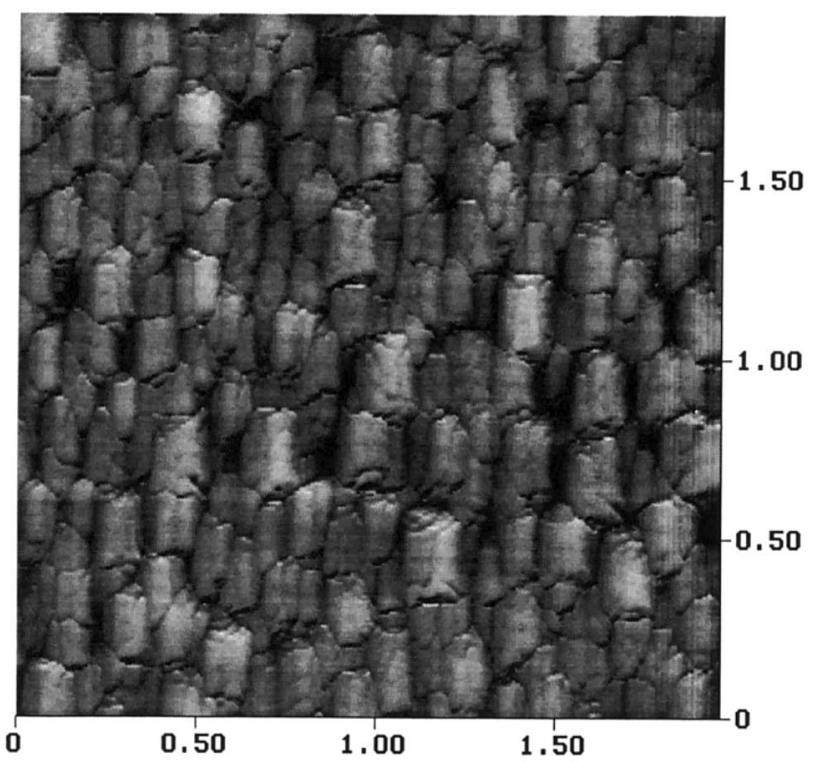

(B)

JM

Fig. 5. AFM image of the iridium UME surface (A) before and (B) after being stored in $0.1 \mathrm{M} \mathrm{HClO}_{4}$ for $2 \frac{1}{2} \mathrm{~h}$ directly under a $\mathrm{Ag} / \mathrm{AgCl}$ (3 $\mathrm{M} \mathrm{NaCl})$ reference electrode.

In further tests to understand the failure mode, a sensor was placed in a solution containing only $3 \mathrm{M}$ $\mathrm{NaCl}$ and acidified to approx. $\mathrm{pH} 2$. Immediately after immersing the sensor into this solution its surface became covered by gas bubbles. The surfaces of the UMEs were clean with no sign of any type of accumulations. When this sensor was tested however, no electroanalytical response could be obtained. Even though the $\mathrm{Hg}_{2} \mathrm{Cl}_{2}, \mathrm{AgCl}$ and $\mathrm{Ag}$ depositions degrade the sensor's response, they are not directly responsible for the catastrophic failure seen. The sensors reaction in the $\mathrm{NaCl}$ solution was overwhelming in producing a total catastrophic failure of the sensor's transduction mechanism.

As will be described below, even though the failure of the sensor occurs in a solution containing $0.1 \mathrm{M}$ chloride ions, the true cause was eventually attributed to the insulating layer on the chip, a materials problem intrinsic to the microfabrication process of these sensors. An iridium UMEA sensor fabricated by a different process using a different metal for the trace connections [10] was tested for comparison. When this sensor was placed in a solution of $8 \mathrm{mM} \mathrm{Hg}, 0.1 \mathrm{M} \mathrm{HClO}_{4}$ and 0.1 $\mathrm{M} \mathrm{NaCl}$, for $2 \frac{1}{2} \mathrm{~h}$, catastrophic failure did not occur. This confirmed that the failure mechanism was most likely linked to the fabrication process. Several differences existed between the two fabrication processes: (1) method of deposition and thickness of the Ir layers (evaporation versus sputtering and 1000 versus 3000 $\AA$ ); (2) the insulating layers; and (3) the material used for the traces (aluminum versus gold). The first difference does not appear to have any relationship to the failure of the sensor in a chloride solution. The second and third differences are crucial to the sensor's performance. If the trace is interacting with the solution, failure is imminent.

In order to verify that the reaction of the aluminum traces with the chloride containing media was the cause of the destruction of the array, a series of experiments were carried out. A galvanic cell was constructed consisting of a piece of aluminum $\left(\sim 2 \mathrm{~cm}^{2}\right)$, an iridium electrode (with a diameter $127 \mu \mathrm{m}$ ) and a solution of 8 $\mathrm{mM} \mathrm{Hg}, 0.1 \mathrm{M} \mathrm{HClO}_{4}$ and $0.1 \mathrm{M} \mathrm{NaCl}$. Upon connecting the cell, the aluminum electrode reacted violently and dissolved. The reaction generated a potential, between the aluminum and iridium electrode of $1.4 \mathrm{~V}$. After approx. $20 \mathrm{~min}$, the electrodes were disconnected and the Ir electrode was placed in $1 \mathrm{M} \mathrm{KSCN}$. When the potential was scanned from -0.3 to $0.3 \mathrm{~V}$ a peak

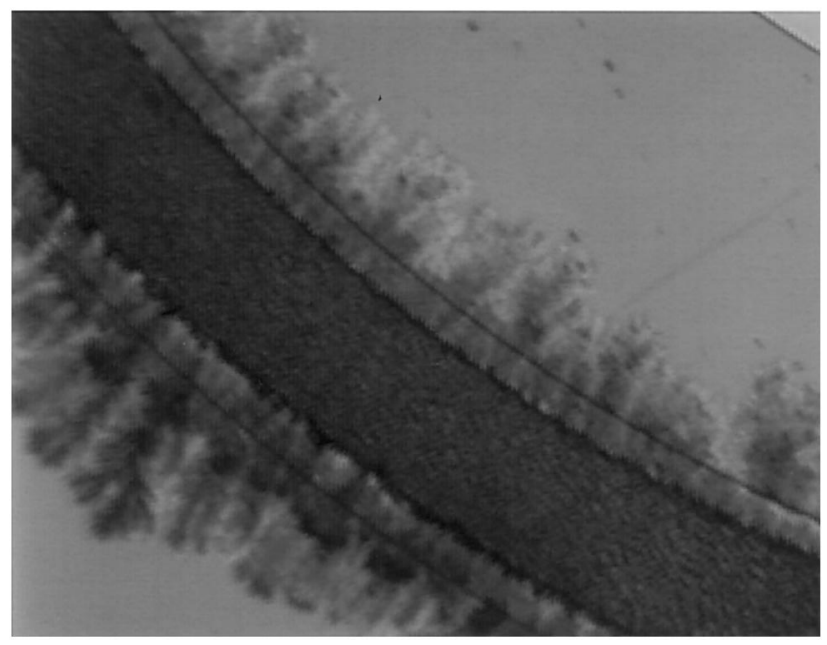

Fig. 6. Array stored in saturated silver chloride solution for $1 \mathrm{~h}$. 
at $0.2 \mathrm{~V}$, corresponding to $\mathrm{Hg}$, was observed. The peak's non-gaussian shape can be attributed to the formation of a $\mathrm{Hg}-\mathrm{Al}$ complex. The charge for the oxidation of the mercury was $41.24 \mu \mathrm{C}$. When both electrodes were again placed in the same solution but with no connection made, the aluminum still reacted but no deposition occurred on the iridium electrode.

In dilute hydrochloric acid solutions, aluminum metal can dissolve to produce hydrogen gas as given by:

$$
\begin{aligned}
& \mathrm{Al}(\mathrm{s}) \leftrightarrow \mathrm{Al}^{3+}+3^{-} \quad \mathrm{E}^{\mathrm{o}}=1.662 \mathrm{~V} \\
& 2 \mathrm{H}^{+}+2 \mathrm{e}^{-} \leftrightarrow \mathrm{H}_{2}(\mathrm{~g}) \quad \mathrm{E}^{\mathrm{o}}=0.0 \mathrm{~V}
\end{aligned}
$$

The actual measured voltage in the experiment above is in reasonable agreement with this reaction and should be more than sufficient to reduce and deposit either mercury or silver ions onto the iridium UMEs for which:

$$
\begin{aligned}
& \mathrm{Hg}^{2+}+2 \mathrm{e}^{-} \leftrightarrow \mathrm{Hg}(0) \quad \mathrm{E}^{\mathrm{o}}=0.851 \mathrm{~V} \\
& \mathrm{Ag}^{+}+\mathrm{e}^{-} \leftrightarrow \mathrm{Ag}(\mathrm{s}) \quad \mathrm{E}^{\mathrm{o}}=0.7996 \mathrm{~V}
\end{aligned}
$$

If the aluminum trace on the sensor chip was somehow exposed to the acidic solution it would be attacked and dissolved, thus the sensor would cease to function. In addition, when mercury or silver ions, were present in the solution the voltage generated from the aluminum reaction was applied to the exposed iridium, which would reduce the $\mathrm{Hg}^{2+}$ or $\mathrm{Ag}^{+}$onto any exposed iridium. It has also been demonstrated by Jagner et al. [14] that under an open-circuit (i.e. no applied potential), $\mathrm{Hg}_{2} \mathrm{Cl}_{2}$ is formed on mercury films when $\mathrm{Hg}^{2+}$ and $\mathrm{Cl}^{-}(0.002$ to $\sim 3.5 \mathrm{M})$ are present.

\subsection{In-situ observations}

Although aluminum was used as the interconnect metal, the insulating layer was presumed to protect the interconnect metal from reacting with the solution. Thus, it was not immediately evident exactly where the gas-producing reaction was taking place. To better observe the location of the gas generating reaction, in-situ observations of the sensor were obtained using a CCD color video camera interfaced with a color video monitor and attached to a VCR.

Before in-situ observations were carried out on the sensor, the aluminum traces on the chip were verified to be intact. When a drop of concentrated hydrochloric acid was placed on the chip, gas bubbles were immediately observed across most of its surface. On closer observation, it was clear that the aluminum traces were dissolving and hydrogen gas was being evolved at those points. The reaction was observed and recorded by the video system. Fig. 7 (a) is a typical frame taken by the video showing the dissolution of an aluminum trace. Clearly, the insulating layer is still intact but the solution has penetrated under the insulating layer in several

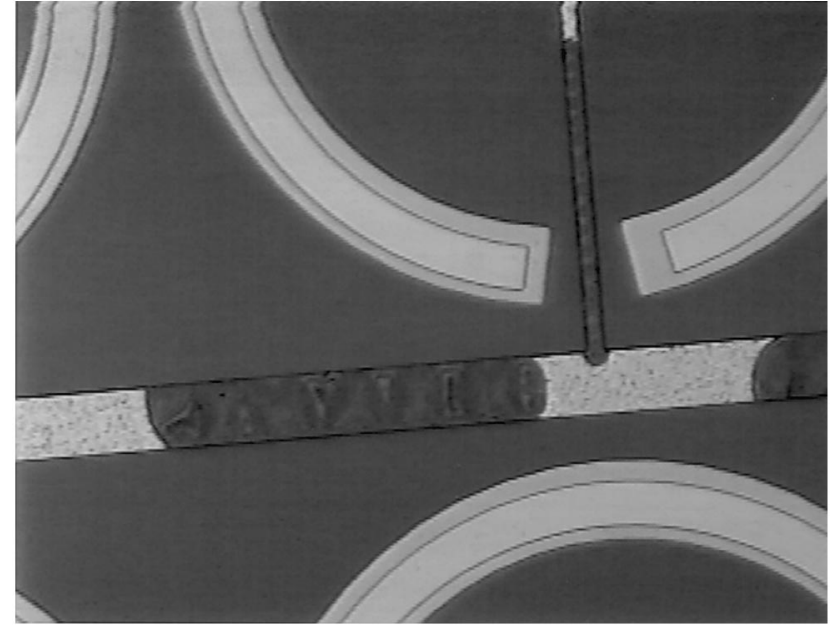

(a)

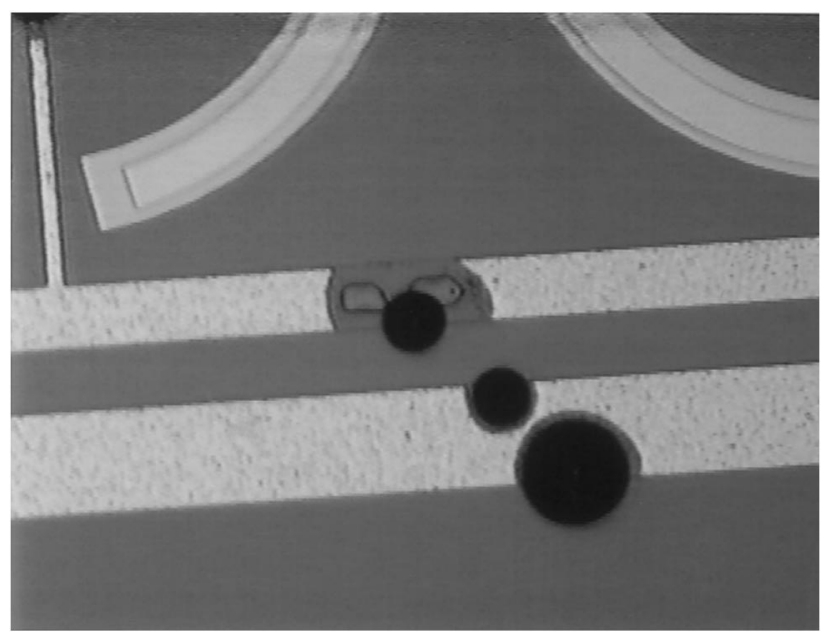

(b)

Fig. 7. In situ observations of an array with a drop of concentrated hydrochloric acid on it. (a) Area where the aluminum dissolved. (b) Aluminum reaction in progress.

locations and dissolved the aluminum trace. Fig. 7 (b) shows the sensor surface at the beginning of the reaction. One can clearly see the gas bubbles being evolved at a single point on the insulating layer. In one instance we can clearly see the formation of a single gas bubble at the same point where the solution has penetrated the insulating material. It is interesting to note that the reaction is occurring under the layer. Apparently the solution has entered the channel at a single pin-hole while the gas appears to be escaping from the same point. This appeared to be the case for almost all the pin-hole reaction sites over the entire sensor, usually one pinhole at each failure point. Even though the failure was widespread and catastrophic, it occurred in two main regions of the circuitry: (1) where the aluminum and iridium overlapped; and (2) at the edges the aluminum traces, areas of thinner insulation.

The mechanism by which the $\mathrm{Cl}^{-}$penetrates the insulating layer is most likely via these sub-micron sized 
pin-holes. This seems reasonable since the failure and the resulting generation of gas, begins at a single distinct location (see Fig. 7b). If the penetration occurred by diffusion, it would most likely be much more widespread and over more irregular areas. In addition, the fact itself that the gas appears to escape through these single pin-holes lends even further weight to this theory. Unfortunately, attempts to provide direct evidence for this mechanism via microscopic observation failed. The pin-holes, due to their size, cannot be observed by optical microscopy. Both SEM and AFM were carried out on these chips but no pin-holes could be seen. However, one problem is the relatively small number of these holes present. There is a very, very, low probability that a pin-hole could be found on the surface within the small micro/nano-meter area observable during each scan by these latter techniques.

An in-situ experiment was carried out with a sensor in which part of the counter electrode was not connected to the aluminum trace. A drop of $8 \mathrm{mM} \mathrm{Hg}$ in $0.1 \mathrm{M} \mathrm{HClO}_{4}$ and $4 \mathrm{M} \mathrm{NaCl}$ was placed on the chip. The counter electrode that was connected to the aluminum trace became covered with accumulation while the area that was not connected to the aluminum trace had none. This points to the reaction with the aluminum as the probable cause for the reduction of the metal ions onto the exposed iridium UME surfaces.

\subsection{Comparison of insulating material}

Since the $2500 \AA$ silicon nitride insulating layer was apparently not effective protecting the aluminum traces, other thicknesses and insulating material were fabricated and tested. Two sensors with a silicon nitride thickness of 1500 and $5000 \AA$ were placed in a $8 \mathrm{mM}$ $\mathrm{Hg}$ in $0.1 \mathrm{M} \mathrm{HClO}_{4}$ and $0.1 \mathrm{M} \mathrm{NaCl}$ solution for $2 \frac{1}{2} \mathrm{~h}$. As with the other insulating layers, accumulations formed on both of these sensors. When the chloride concentration was lowered to $0.01 \mathrm{M} \mathrm{NaCl}$, no accumulations were observed. Thus, the thickness of the insulating layer does not appear to inhibit the failure of the sensor. Another sensor fabricated with a $5000 \AA$ thick silicon dioxide insulating layer was also tested. However, the same failure was seen for this one when placed in the same solution as above. The destruction of the array was not prevented by either the insulating material or its thickness.

\section{Conclusion}

The failure of these microlithographically fabricated Ir-UMEA sensors appears to be due to the penetration of chloride ions through the insulating layer, most likely through sub-micron sized pin holes. The aluminum interconnect traces react with the acidic chloride solution and dissolve. Because of the potential generated by the aluminum reaction, metals ions such as mercury or silver present in the solution are reduced onto the exposed iridium surfaces. Several insulating materials, silicon nitride (1500, 2500 and $5000 \AA)$ and silicon dioxide (5000 $\AA$ ) were tested but none of them offered any better protection. It would appear that it is critical that sub-micron sized pin-holes during the fabrication process be better controlled. One way to possibly decrease the amount of pin-holes in the insulating layer would be to deposit the insulating material in two steps. This would decrease the likelihood of a pin-hole being formed in the same place during both deposition steps. Also, other insulating materials such as polyimide may provide better protection of the aluminum trace. In most cases this requires extra steps during the fabrication process and could substantially increase the cost. A lower cost solution may be to use a non-reactive metal such as gold for the interconnect traces on the sensor chips. However, in some situations, the pin-holes may act as UMEs and provide an unwanted contribution to the electroanalytical signal. In most cases though, the insignificant amount of exposed electroactive surface may not interfere.

\section{Acknowledgements}

This work was supported in part by Grants from the Environmental Protection Agency through the Northeast Hazardous Substance Research Center and the National Science Foundation (CHE-9256871). The authors would like to thank the Center for Materials Science and Engineering (MIT), particularly Elisabeth Shaw for her help in obtaining the Auger SEM data and the Microsystems Technology Laboratories (MIT) for providing the microlithographic fabrication of the UMEA chips. We also thank Rosemary Feeney for her valuable assistance.

\section{References}

[1] A. Uhlig, U. Schnakenberg, R. Hintsche, Highly sensitive heavy metal analysis on platinum- and gold-ultramicroelectrode arrays, Electroanalysis 9 (1997) $125-129$.

[2] G. Sreenivas, S.S. Ang, I. Fritsch, W.D. Brown, G.A. Gerhardt, D.J. Woodward, Fabrication and characterization of sputteredcarbon microelectrode arrays, Anal. Chem. 68 (1996) 18581864.

[3] M. Paeschke, F. Dietrich, A. Uhlig, R. Hintsche, Voltammetric multichannel measurements using silicon fabricated microelectrode arrays, Electroanalysis 8 (1996) 891-898.

[4] R. Wehrens, W.E. van der Linden, Calibration of an array of voltammetric microelectrodes, Anal. Chim. Acta 334 (1996) 93101.

[5] C. Belmont, M.-L. Tercier, J. Buffle, G.C. Fiaccabrino, M. Koudelka-Hep, Mercury-plated iridium-based microelectrode ar- 
rays for trace metals detection by voltammetry: optimum conditions and reliability, Anal. Chim. Acta 329 (1996) 203-214.

[6] C.D.T. Bratten, P.H. Cobbold, J.M. Cooper, Micromachining sensors for electrochemical measurements in subnanoliter volumes, Anal. Chem. 69 (1997) 253-258.

[7] H. Sangodkar, S. Sukeerthi, R.S. Srinivasa, A.Q. Contractor, A biosensor array based on polyaniline, Anal. Chem. 68 (1996) $779-783$

[8] V.B. Nascimento, M.A. Augelli, J.J. Pedrotti, I.G.R. Gutz, L. Angnes, Arrays of gold microelectrodes made from split integrated circuit chips, Electroanalysis 9 (1997) 335-339.

[9] J. Herdan, R. Feeney, S.P. Kounaves, A.F. Flannery, C.W. Storment, G.T.A. Kovacs, R.B. Darling, Field evaluation of an electrochemical probe for in-situ determination of heavy metals in ground water, Environ. Sci. Technol. 32 (1998) 131-136.

[10] G.T.A. Kovacs, C.W. Storment, S.P. Kounaves, Microfabricated heavy metal ion sensor, Sensor and Actuators B 23 (1995) 41-47.

[11] S.P. Kounaves, W. Deng, P. Hallock, G.T.A. Kovacs, C.W. Storment, Iridium-based ultramicroelectrode array fabricated by microlithography, Anal. Chem. 66 (1994) 418-423.

[12] M.A. Nolan, S.P. Kounaves, Effects of mercury electrodeposition on the surface degradation of microlithographically fabricated iridium ultramicroelectrodes, J. Electroanal. Chem. (in press).

[13] R. Feeney, J. Herdan, M.A. Nolan, S.H. Tan, V. Tarasov, S.P. Kounaves, Analytical characterization of microlithographically fabricated iridium-based ultramicroelectrode arrays, Electroanalysis 10 (1998) 89-93.
[14] D. Jagner, E. Sahlin, L. Renman, Apparent formation of an oxidant by electrochemical reduction in the mercury $(0$, I, II) chloride system, Anal. Chem. 68 (1996) 1616-1622.

\section{Biographies}

Melissa A. Nolan was born in Revere, MA in 1972. She received her B.S. in chemistry with honors from Utica College of Syracuse University in 1994. She is currently pursuing a Ph.D. in analytical chemistry at Tufts University. Her research focuses on the use of AFM, optical microscopy and electrochemical methods for the surface characterization of electrode substrates.

Samuel P. Kounaves received his BS/MS in Chemistry from California State University at San Diego in 1976/ 78 and his Ph.D. in 1985 from Université de Genève, Geneva, Switzerland. After post-docs at SUNY Buffalo and Harvard University he joined the faculty at Tufts University in 1988 were he is currently an Associate Professor of Chemistry. His main research interests are in research and the application of modern electrochemical techniques to analytical, environmental and materials problems. 